\title{
Performing More-Than-Human Corporeal Connections in Kiki Smith's Sculpture
}

\section{ABSTRACT}

The article examines work by contemporary American artist Kiki Smith, who proposes a future in which human and nonhuman bodily borders merge. The artist's contribution to the more-than-human artistic entanglements is juxtaposed with Joseph Beuys's artistic manifesto from 1974 which proposes, among other things, an attempt to get outside of the represented human towards the asignified ahuman. In Kiki's sculpture, both human and nonhuman animals undergo constant morphogenesis, becoming hybrid forms far beyond the human-social paradigm, implying that the human and nonhuman binary, due to the exchange of affective entanglements, is no longer valid in the heyday of techno-scientific development. The analyzed work shows that both human and nonhuman bodies are raw materials not separated from one another but always interconnected with the world and its ongoing material processes. Thus, the article emphasizes that it is only through the transgression of the human and nonhuman border that one can acknowledge the more ethical and political ways of cooperation needed for the appreciation of the multispecies dimension of our world and its survival.

Keywords: performative arts, more-than-human entanglements, American art, Kiki Smith, Joseph Beuys. 
"To live under biopolitics is to live in a situation in which we are all always already (potential) 'animals' before the law—not just nonhuman animals according to zoological classification, but any group of living beings that is so framed." (Wolfe 10)

\section{INTRODUCING MORE-THAN-HUMAN CONNECTION IN ARTISTIC PRACTICES}

When German artist Joseph Beuys reached America for the first time in May 1974 to perform his artistic action, no one expected that he would spend three days enclosed in a room in West Broadway's René Block Gallery with a coyote from Phifer's Animal Farm in Gillette, New Jersey. Much to everyone's surprise, the artist did not explore the country and its culture; rather, once he landed at JFK, he was wrapped in felt, laid on a stretcher and driven by ambulance to the gallery where the coyote, which was his sole companion for three days, was awaiting him. To offer more natural surroundings to the nonhuman animal, the artist arranged strips of felt in the space and spent almost the entire time sitting and forging the connection between the coyote and himself. The only remaining objectsthe remnants of our civilization-were his brown gloves, a flashlight and a walking stick to lean on. Soon, the process of observing and forging close bodily and audio connections with the coyote started. Though sacred to the Indians and one of their gods' mightiest creatures, the animal was labeled an antisocial menace-the mean coyote-when the white man appeared on the continent. The animal's status did not discourage the artist; for three days and nights, Beuys talked to the coyote, choreographed some movements and encouraged the animal to tug at the felt strips. From time to time, he even produced some sounds for his nonhuman companion, playing a triangle which he wore suspended around his neck. Eventually, they forged a strong bond and exchanged their beddings, which was a sign that the two had got used to each other. Then, Beuys ${ }^{1}$ hugged the animal and left the gallery. Wrapped back in felt, he was taken directly to JFK airport.

As the artist highlighted, the action entitled I Like America and America Likes $M e$ was a form of social sculpture, understood here as an organic forming from the inside out that was meant to concentrate predominantly on the coyote rather than the artist himself. To achieve this, as he pointed out, "I wanted to isolate myself, insulate myself, see nothing

1 It has to be highlighted that Beuys, in cooperation with his students, was the founder and initiator of the first political party for animals in 1969. His engagement subsequently resulted in the formation of the Green Party in Germany. 
of America other than the coyote" (Stachelhaus 174). For the artist, who was a stranger in the metropolitan setting and represented the voice of those who immigrate to the USA, the coyote embodied the continent's deep trauma, the extermination of indigeneity and the destruction of natural surroundings. Beuys explained that through his action he felt he affected the course of the history of the United States and as he asserted: "I believe I made contact with the psychological trauma point of the United States' energy constellation: the whole American trauma with the Indian" (Tisdall 228). The dialogue between the coyote, here representing the Native Americans, and the artist, representing the Europeans, resembled a shamanistic revision of the history in which the synergy between the two replaced the violence imposed from above. More importantly, to leave the socio-cultural context and its re-readings, Beuys's performative action indicated that the establishment of the human and the nonhuman animal relation, which has been enduringly problematic to accept in humanities' conceptual framework, requires from us activism and eco-thinking beyond the limitations and norms imposed by socio-cultural structures. With grace and engagement, he defied the very concept of human and nonhuman borders, turning the human role away from its focal point and thus redefining the role of more-than-human elements in our conceptual thinking. What was crucial in the process was the material (the part of objects and their materiality), bodily manifestations of thought that allowed him to merge ethics with aesthetics. Beyond discursive, institutional and representation processes, which validate the humanist project, Beuys's performative action becomes a more-than-human/humanist practice. In effect, through direct corporeal engagement that allowed him to be morethan-human in the world, his activism triggered new forms of productive relations globally, rejecting old patterns of enunciation and imposition of power over the nonhuman.

What particularly interests me in this performative action and its strategies of resistance is the formation of this connective environment, in which both of the actors-human and nonhuman animal-became equal agents of the artistic practice. The interaction with the nonhuman animal based on habit formation and communication experiments brought about a subversion of the human/nonhuman corporeal border. In consequence, the action allowed Beuys, a foreigner in the American setting, to manifest his artistic philosophy which reveals his ideas on how to heal western minds governed by mechanisms of socio-cultural exclusion and constant persecution of the marginalized (both human and nonhuman). Not only was his performance an exercise in connection with the nonhuman animal world and the interrogation of how apparatuses of anthropocentrism produce and police a borderland in which human and nonhuman worlds 
coexist; it also suggested that nonhuman animals, refugees, immigrants, war veterans and ethnic minorities share the same plight, undergoing marginalization in the socio-cultural realms. To be more precise, his action revealed that exploitation and exclusion are not only territorial but that they are also equally directed at multispecies. Beuys proposes that the morethan-human perspective allows one to discern how conceptual binaries are constructed and enacted. Having realized the impact of our anthropocentric thinking on the position of the more-than-human world, it is easier to confront oneself with all the response-ability with/for its survival, which is understood by Donna J. Haraway as "collective knowing and doing, an ecology of practices" (Staying with the Trouble 34). It is worth emphasizing that, for Haraway, response-ability is not merely an individual's response towards situations; on the contrary, it is the cultivation of the readiness to take actions collectively when needed. In this respect, having realized how human power is exercised over nonhuman life, it is easier to understand the plight of the marginalized.

\section{PLAYING STRING FIGURE GAMES TO MAKE KIN WITH THE MORE-THAN-HUMAN}

"Play is the practice that makes us new, that makes us into something that is neither one or two, that brings us into the open, where purposes and functions are given a rest. Strangers in hominid and candid mindful flesh, we play with each other and become significant others."

(Haraway, Staying with the Trouble 458)

The more-than-human approach has been employed by various feminist scholars within posthumanist studies who interrogate human and nonhuman animal interconnection (Haraway, "Training"; Despret; Adams and Gruen). Donna Haraway, in her book Staying with the Trouble. Making Kin in Chtbulucene, for instance, emphasizes that this is the multispecies alliance that can allow us to acknowledge the interdependence of nature, culture, and technology. Socio-cultural awareness of multispecies companionship_and thus, a transdisciplinary/transspecies perspectiveenables one to think collectively not from a position of the domination of the empowered but rather to see the world as interconnected. Thus, it can be asserted that multispecies relationality means becoming with the world's ongoing processes. Haraway discloses her point, providing readers with an anthropological insight into the mechanisms of string figure games, well-known in most cultures of the globe, to illustrate the 
connections. The simple game, which is played by weaving a single loop of string on the hands to produce intricate patterns supposed to represent particular familiar objects, enhances not only collective thinking but also the movement in complexity and diversity. As the philosopher points out,

playing games of string figures is about giving and receiving patterns, dropping threads and failing but sometimes finding something that works, something consequential and maybe even beautiful, that wasn't there before, of relaying connections that matter, of telling stories in hand upon hand, digit upon digit, attachment site upon attachment site, to craft conditions for finite flourishing on terra, on earth. String figures require holding still in order to receive and pass on. String figures can be played by many on all sorts of limbs, as long as the rhythm of accepting and giving is sustained. (Staying with the Trouble 10)

In other words, players, while interacting, unfold their stories, making nonverbal connections, exchanging patterns of giving and receiving. Joseph Beuys explored this relation while he was forming mutual habits with the coyote; though unable to play the game in this context, the artist used similar rules and patterns to connect with the animal. In a sense, the artist's action reminds us of Haraway's writings in which a coyote becomes a trickster "who constantly scatters the dust of disorder into the orderly star patterns made by the Fire God, setting up the non-innocent world-making performances of disorder and order that shape the lives of terrain-critters" (Staying with the Trouble 14). The coyote is the one from the peripheries, with the secret knowledge that reminds us that sociocultural structures, though ordered and well-composed, are, under the surface, riddled with violence against the least privileged. However, it may be anticipated, following Brian Massumi, that it is through play that "the human enters a zone of indiscernibility with the animal. When we humans say 'this is play,' we are assuming our animality. The play dramatizes the reciprocal participation of the human and the animal from both sides. For when animals play, they are preparatorily enacting human capacities" (8). Beuys's play with the coyote was an example of the pure exchange of energy and spatial-temporal acts that enabled both players to cross physical borders and divisions imposed by socio-cultural norms. In this way, since verbal communication was limited, nonverbal patterns played a more significant role, allowing the players to become-with (Haraway, When Species Meet) each other, not just to be.

The performance was not only about "thinking together anew across differences of historical position and kinds of knowledge and expertise" (Staying with the Trouble 25); it was predominately a new form of corporeal collaboration established irrespective of the similarities and 
differences that both agents had to encounter. The artist's connection with the coyote, to invoke Haraway, was an effect of the fact that "string figures are like stories; they propose and enact patterns for participants to inhabit, somehow, on vulnerable and wounded earth" (Staying with the Trouble 26). The collaboration, the co-creation, resulted from material and semiotic combinations that activated the agents' bodies, leaving inner blockages outside to form more-than-human relations. In this respect, as the philosopher points out, making kin with the nonhuman can "still [be] a risky game of worlding and storying; it is staying with the trouble" (Staying with the Trouble 13). In other words, the revealing of the hidden, which constitutes repressed stories of exclusion and repression, may lead to further dire straits that open up thresholds of our sustainability. However, in line with Rosi Braidotti's thought, it may be concluded that the poetics of sustainability here entails the necessity of containing the other, the suffering, the enjoyment, the organic and nonorganic, allowing subjects to redefine the same-other relation, affecting and being affected by others through mutually dependent correlation (Nomadic Theory).

Human and nonhuman interconnectedness transgresses all borders and reveals the unseen sights of our becoming. For Haraway, these forms of interaction exemplify sympoiesis, "collectively-produced systems that do not have self-defined spatial or temporal boundaries. Information and control are distributed among components. The systems are evolutionary and have the potential for surprising change" (Staying with the Trouble 33). By contrast, as she explains, our culture is dominated by autopoietic systems that are "self-producing" autonomous units "with self-defined spatial or temporal boundaries that tend to be centrally controlled, homeostatic, and predictable" (Staying with the Trouble 34). In this sense, more-than-human relations are sympoietic practices, which aim to generate other potentialities and multiplicities, rather than self-centered acts. ${ }^{2}$ Since multiplicities in Deleuzian terms are the potentials/movements for change, it may be deduced that multiplicity becomes a performative concept as it needs to be continuously activated. The artistic practices concentrated on forming more-than-human corporeal bonds remind us of string figure games that explore new patterns of interaction. Once they have been initiated, the games may show ethical routes of care and understanding of the minor. The equality stems from the fact that "companion species play

2 As Rosi Braidotti notices, Donna Haraway's theories emphasize that multiplicity need not necessarily lead to relativism. Quite on the contrary, "Haraway argues for a multi-faceted foundational theory, for an anti-relativistic acceptance of differences, so as to seek for connections and articulations in a non-gender-centred and non-ethnocentric perspective" ("Feminist Philosophies" 210). 
string figure games where who is/are to be in/of the world is constituted in intra-and interaction. The partners do not precede the knotting; species of all kinds are consequent upon the worldly subject- and object-shaping entanglements" (Staying with the Trouble 13). In other words, we, as humans, need to recalibrate our perspectives in order to recognize a broader range of terrains and territories full of nonhuman agents. This is an action against the limits of humanist vision that only sees humans as social creatures and nonhumans as connected with nature, and which, as Patricia MacCormack aptly summarizes, "involves forsaking the privilege of human social power, including all degrees of majoritarian to minoritarian, which delimits desire to one between humans as viable objects of desire or facilitators of acts, including one's self as both subject-object and facilitator. In this way, the human becomes the ahuman anonhuman" (127). Therefore, when we refer back to the quotation opening the article, it may be deduced that, as a vehicle of our ethic-aesthetic transformation, the adoption of any form of individual play may facilitate many changes and potentialities, for, once again following Brian Massumi, play is made of performative gestures exerting a transindividual force (5).

\section{BECOMING-ANIMAL AND CORPOREAL CONNECTIONS IN ARTISTIC PRACTICES}

The question now arises of how contemporary artists "stay with the trouble" and "play string figure games" in order to respond to more-thanhuman connections during the techno-scientific turn. Do sympoietic artistic practices resonate with the complexities of today's world? Can performative actions evoke the complexities of the reconfiguration of bodies in recent times? I would like to apply the Harawayan trope of "staying with the trouble" and "playing string figure games" to analyze artistic works that are not accurate representations of human and nonhuman animal corporeal relations but rather address a transposition between human and nonhuman animal bodies (and other simple forms of life). These are projects inspired by the potential of new bio-scientific-inter aliadevelopments and heretofore take art into unimaginable directions where the vision of what it means to be human is radically abandoned. While blurring the boundaries between human and nonhuman worlds, the artists often produce mutations, manipulations and transpecism to de-familiarize the standards in representation of the human and emphasize the ethical impact of technological interference into the organic world. The works often reflect the scientific procedures of encountering the human with the nonhuman elements, implying that life is all about becoming rather 
than being. The article does not aim to trace the historical discussion of what is animal versus what is human. The line of argumentation of the article corresponds here to Deleuze and Guattari's concept of becominganimal ${ }^{3}$ which "does not consist in playing animal or imitating an animal, it is clear that the human being does not 'really' become an animal any more than the animal 'really' becomes something else. Becoming produces nothing other than itself" (A Thousand Plateaus 238). In other words, this is becoming-with the nonhuman animal, not identifying with it and producing an anthropocentric imitation. As Deleuze and Guattari indicate in their Kafka: Toward a Minor Literature (1986), the becoming stems from the fact that

there is no longer man or animal since each deterritorializes the other in conjunction with flux, in a continuum of reversible intensities. Instead, it is now a question of a becoming that includes the maximum of difference as a difference of intensity, the crossing of a barrier, a rising or a falling, a bending or an erecting, an accent on the word. The animal does not speak "like" a man but pulls from the language tonalities lacking in signification; the words themselves are not "like" the animals but in their way climb about, bark and roam around, being properly linguistic dogs, insects, or mice. (22)

The work of the American contemporary artist, Kiki Smith, analyzed in this article is experience and practice with human body and its potentials to relate and spatialize with the nonhuman animal in order to evoke the ahuman character present in everyone. As there is no physical barrier between the two, the bodies are deterritorialized, never imitated. Nevertheless, in contrast to Beuys's performative action, Kiki Smith often uses sculpture, robotics and other devices to emphasize the importance of materiality in technological processes. The article indicates that the artistic experiment explores spatial-corporeal encounters between more-thanhuman bodies to embrace the ahuman character of transgressing all the socio-cultural barriers. While unfolding my line of argumentation, I will suggest that a more-than-human body, in the analyzed work, is "a mutual constitution of entangled agencies” (Barad 33), always dynamic and open to further modifications. Hence, the article proposes that through its engagement with the more-than-human elements, the body forms multispecies connections and thus disposes of adverse effects produced by socio-cultural discourses.

3 It is worth highlighting that becoming-animal for Deleuze and Guattari "does not exemplify anything animal per se (either of an individual or a species), but human apprehensions of affects of animality" (MacCormack and Gardner 4). 


\section{KIKI SMITH'S RAPTURES IN NONHUMAN CORPOREAL BORDERLANDS}

Contemporary American artist Kiki Smith has investigated more-thanhuman entanglements for many decades. Some of her prints, sculptures and drawings plunge into borderlands where the division into human and nonhuman does not exist. The world in her works, which is almost on the verge of fantasy and fairy tales, undergoes the process of metamorphosis, thanks to which living forms mutate and modulate. There is, however, no mayhem in her vision; all the creatures are equal, and the natural cycles of regeneration and renewal open up new possibilities of the world's forms to come. While exploring more-than-human connections/becomings, the artist transfigures the classical approach towards the monstrosity and bestiality of nonhuman animals, ${ }^{4}$ giving them a human touch and sensitivity. This stems from the fact that, as Marina Warner asserts, "attitudes towards beasts in Smith's works are continually entangled with ideas about ourselves as humans concerning them, and about where boundaries lie and how the classifications establish hierarchy" ("Metamorphoses" 31). Smith subverts the maintained order and thus the classical legacy of myths and various symbols that promote humans' superiority in western cultures. Stripped of negative connotations, nonhuman animal and human hybrids naturally occur in her projects, corresponding preferably to the ongoing cycles of the world's changes rather than to foundational mythologies. In this way, her works suggest that these bodily mergers have always been present. Furthermore, while commenting on the language of metamorphosis, Smith once remarked to her fellow artist Chuck Close that "you have a certain amount of regrowth. Like reptiles whose tails grow back, or a worm cut in half. We do not tend to think of that, regeneration" (Warner, "Wolfgirl" 44). Metamorphosis and regeneration in most of her art works appear to be naturally generated processes that transform the matter, creating an impression of constant "becoming."

Before I proceed to analyze Smith's works, in which more-thanhuman entanglements prevail, it has to be emphasized that Smith, acclaimed as a feminist artist, at one point devoted her output mainly to the investigation of the human body, which she has treated as a vehicle for exploring the human condition, spirituality and vulnerability. Having started to experiment with the material structures of the female corpus, the digestive system and bodily fluids_-blood, sweat, milk and tears (treating

4 What is meant here by the standard ways of representing monstrosity is the fact that Smith's beasts do not embody any danger to humans. Contrariwise, as is highlighted mainly in her prints and drawings, there is an ongoing conversation between the two to indicate their inextricable linkage and connection. 
the body as a system) - her works were soon labeled "body art" and have been often discussed in the context of AIDS studies, sexuality and gender performativity. More importantly, however, fragmented, fragile and abject, the human body in her works has always been negotiating with the flesh of the world, as if trying to prove that the materiality of both is not at all separate. When presenting female bodies, she diligently studies their biological structures and functions almost with microscopic precision. Her immersion in bodily processes implies that her projects are attempts to respond to Maurice Merleau-Ponty's question from his essay "The Intertwining-The Chiasm": "where are we to put the limit between the body and the world since the world is the flesh?" (138). Smith sees the flesh as a connector rather than a boundary with the other. She constructs and deconstructs the body in such a way as to extend it into the outside world and prove that its material and psychic structure constitutes an integral part of the world's ongoing processes. The approach corresponds to what Merleau-Ponty understands as the flesh, material and psychic support for the self, "metaphorically as well as materially, and the flesh is an envelope, a 'limit' inscribing the juncture between inside and outside but also the site of their joining" (qtd. in Jones 207). In other words, her works are attempts to produce a sympoietic practice of treating the human body as the becoming-with-the world and thus seeing it from the inseparable from the more-than-human constituents of our lives. However, Smith's works transcend the phenomenological perspective-which traces how humans are embedded socially, culturally, psychologically and materially in the world-producing an anti-anthropocentric voice and recognizing morethan-human phenomenology.

Having explored the dynamism of bodily transformations in her works, the artist entered her next stage, during which she absorbed herself with the question of the animal in the human. Her stunning life-size bronze sculpture Rapture (2001), showing a full-blown woman emerging from a wolf's split-open belly, aptly investigates more-than-human physical connections. Despite the solidity of the material, there is a subtle movement in the sculpture that produces an impression of the presented scene's fragility during which the woman is stepping forward from the animal, while her left leg remains inside the wolf. Delicate and smooth, the structure of the woman's body is juxtaposed with the rough and heavily textured fur of the wolf. The only element that structurally joins the two bodies is the pubic hair of the female which introduces an organic balance to the whole composition, placing the wombs of both the human and nonhuman animals as the focal points of the entire composition and suggesting that the movement of metamorphosis starts and ends here. This, combined with the cautious emergence of the female figure from 
the nonhuman companion's womb, highlights the naturalness of the ongoing material process, highlighting that the human body is part of an active material world of nonhuman becoming. However, the work is not simply an encounter with the animal; on the contrary, it becomes a mutual metamorphosis for both. In effect, Smith's work becomes a morphological hybrid that erases bodily boundaries between the animal and the woman as they both materially depend on one another, radically erasing the otherness, "physical proximity and (near) contact with the flesh of the animal Other" (Broglio 60). In a Deleuzean-Guattarian sense, Smith proposes becomingwoman/animal not as predicated on the stable and centralized self of the human but rather on a non-unitary dynamic subject that connects to a depersonalized subject. In other words, the sculpture indicates, following Deleuze and Guattari, that

the self is only a threshold, a door, a becoming between two multiplicities. Each multiplicity is defined by a borderline functioning as Anomalous, but there is a string of borderlines, a continuous line of borderlines (fiber) following which the multiplicity changes. And at each threshold or door, a new pact? A fiber stretches from a human to an animal, from a human or an animal to molecules, from molecules to particles, and so on to the imperceptible. (A Thousand Plateaus 249)

As the woman in Smith's work is inextricably linked with the nonhuman animal, becoming together with/from it, the sculpture indicates that the subject is fully immersed in the nonhuman relations that need to be continuously reactivated by getting rid of anthropocentric framing. This is in line with the artist's claim that the work is related to both the medieval legend of St. Genevieve, born from a wolf's womb, and Little Red Riding Hood, and it is a kind of resurrection/birth myth (Zipes 18). Indeed, it may be asserted that Smith's sculpture is the rebirth of morethan-human beings as there is no difference in size and value of the human and nonhuman agents; they both equally constitute the world's fabric and its visage.

The figure of the wolf can be a crucial trope in Deleuze and Guattari's theory of becoming-animal. Antithetical to psychoanalytic insights, the metaphor helps the philosophers to unfold the map of nonhuman becoming. ${ }^{5}$ Unlike the psychoanalytic perspective, which uses anthropomorphized wolves to confirm their role in the symbolic order, the philosophers' notion is shifted to non-anthropocentric ends. In other

5 Deleuze and Guattari devoted a whole chapter of A Thousand Plateaus, "1914: One or Several Wolves," to explain "becoming-wolf," referring to Sigmund Freud's patient nicknamed Wolf-Man. 
words, the wolf does not represent humans' fears of their instincts, such as sexual desire, hunger, passion for nature, and primitive forms ingrained in us by socio-cultural norms. Rather, the metaphor in their book enables Deleuze and Guattari to indicate the normative confines of oneself, which was also clearly stated in Joseph Beuys's action. In effect, the philosophers open up humans to the aberrated otherness/nonhuman. The widely recognized image of the wolf, dominant in western classical mythologies and fairy tales associated with sexual aggression, violence and the seduction of helpless women, has thus been transgressed by Deleuze and Guattari's critique of the psychoanalytic binary distinction and singularity of the human form. The philosophers focus instead on the becoming-animal that involves "pack, a band, a population, a peopling, in short, a multiplicity" (A Thousand Plateaus 239). "Becoming animal" requires non-hierarchical participation and relationship with the nonhuman multiplicity, for Deleuze and Guattari consider nature not as a hierarchy, but as a multiplicity, a life without subjects and objects. This is an entirely different way of thinking about life as it is based on the connections that introduce a transspecies consciousness, eliminating western distinctions and the privileges attributed to the human. Hence, it may be asserted that Smith's work is not just an encounter with otherness/the nonhuman animal but is predominantly a material becoming out of/with the wolf, indicating that non-subjective individualities can bring more potential to the ethical understandings of our shared existence.

The title of Smith's work, Rapture, brings to mind Deleuze and Guattari's concept of rapture lines ${ }^{6}$ (also called lines of flight) responsible for deindividuated becoming. As Luis de Miranda notices, a rapture line is "a force of impetuous attraction, the torrent of an over-full life (but not always a fool's life) bursting beyond the preservation necessity of the individual belonging to a species" (108). The rapture produces transspecies experience that widens one's horizons and thus brings us closer to the ahuman position. Furthermore, in Smith's sculpture, the transspecies interdependence without any hierarchy is established owing to the rapture lines, disintegrating elements of the structural order. The woman and the wolf's body/bodies transform, deterritorializing7 their social, perceptual, conceptual and historical functions and formats. In this manner, the sculpture traverses individual and collective subjectivities to combine

6 In other words, Deleuze and Guattari contrast the rapture line with the molar one that is the vital line of dominance and order. The rupture is the energy line of the multiversal monster.

7 For Deleuze and Guattari, deterritorialization can be understood as a movement that produces changes and fluctuations to the organization of life structures. It frees all the fixed relations, bringing the potentials. 
various human and nonhuman affects and percepts in ways that conjugate one another. This is in line with Deleuze and Guattari's understanding of the conditions of the process of becoming-animal. As the philosophers highlight, if becoming-animal "takes the form of a temptation, and of monsters aroused in the imagination by the demon, it is because it is accompanied, at its origin as in its undertaking, by a rupture with the central institutions that have established themselves or seek to become established" (A Thousand Plateaus 247). The human is "raptured" here, as the nonhuman animal and the sculpture's material structure become equal agencies in the material and thus the socio-cultural process of more-thanhuman-becoming.

\section{CODA: PERFORMING MORE-THAN-HUMAN/ REPRESENTATIONAL ENTANGLEMENTS}

To conclude, I would like to refer again to the film documenting Joseph Beuys's performative action, in which he defines the concept of the social sculpture. As he asserts, if artists want to heal western minds, they need to infiltrate the institutions of science, religion, architecture and politics. Beuys, contrary to expectations, entered into dialogue with the system not via discursive critique but through a playful game with the western world's central theoretical and practical tenets, indicating the humanist project's failures. Hence, the categorizations of nonhuman animal in our perceptual thinking were unpacked, and the creative human-nonhuman interactions, which opened a space for the emergence of unexpected affections and connections, were activated. His sympoietic engagement with the nonhuman animal proved essential to produce a new quality of affirmative ethics based on relational rather than exclusive politics. Also, Kiki Smith's sculpture-though more contemporary and totally different in its material methodologies-presented micropolitical experiments, investigating what bodies can become and how humans and animals can live together (Bennet) in the age of post-biological times. Her work is a form of becoming with and for the animal, focusing on more complex conceptions of human bodies' materiality and the more-than-human world than the traditional perspectives based on representation methods and the denial of nonhuman agencies. Hence, the artist proposed more-than-representational plans to evoke a human character that can allow us to understand, challenge the ontologies of humanism rooted in binary oppositions, and subsequently leave behind the free vectors of power responsible for the formation of our socio-cultural framework. The work demonstrates that embodied, affective and more productive encounters with nonhuman life bring new 
forms of posthuman ethics—conceptualized by Patricia MacCormack-as a set of new relations that offer liberty and deeper contemplation of the systems of power. One thing seems certain: one has to reach the ahuman level, apply ethical rules of care, and finally relegate humans' position in order to fully appreciate and understand the complexity of our more-thanhuman entanglements.

\section{Works CiTED}

Adams, Carol J., and Lori Gruen, editors. Ecofeminism: Feminist Intersections with Other Animals and the Earth. Bloomsbury, 2014.

Barad, Karen. Meeting the Universe Halfway. Quantum Physics and the Entanglement of Matter and Meaning. Duke UP, 2007. https://doi. org/10.1515/9780822388128

Bennett, Jane. Vibrant Matter: A Political Ecology of Things. Duke UP, 2010. https://doi.org/10.1515/9780822391623

Braidotti, Rosi. "Feminist Philosophies." A Concise Companion to Feminist Theory, edited by Mary Eagleton, Blackwell, 2003, pp. 195-214. https://doi.org/10.1111/b.9780631224037.2003.00012.x

Braidotti, Rosi. Nomadic Theory: The Portable Rosi Braidotti. Columbia UP, 2011.

Broglio, Ron. Surface Encounters: Thinking with Animals and Art. U of Minnesota P, 2011.

Deleuze, Gilles, and Felix Guattari. A Thousand Plateaus. Capitalism and Schizophrenia. Translated by Brian Massumi. U of Minnesota P, 1987.

Deleuze, Gilles, and Felix Guattari. Kafka: Toward a Minor Literature. Translated by Dana Polan. U of Minnesota P, 1986.

De Miranda, Luis. "Is a New Life Possible? Deleuze and the Lines." Deleuze Studies, vol. 7, no. 1, 2013, pp. 106-52. https://doi.org/10.3366/ dls.2013.0096

Despret, Vinciane. "The Body We Care for: Figures of Anthropo-zoogenesis." Body E Society SAGE Publications, vol. 10, no. 2-3, 2004, pp. 111-34. https://doi.org/10.1177/1357034X04042938

Haraway, Donna J. Staying with the Trouble. Making Kin in Chtbulucene. Duke UP, 2016. https://doi.org/10.1515/9780822373780

Haraway, Donna J. "Training in the Contact Zone: Power, Play, and Invention in the Sport of Agility." Tactical Biopolitics: Art, Activism, and Technoscience, edited by Beatriz da Costa and Kavita Philip, The MIT P, 2008, pp. 445-65. https://doi.org/10.7551/ mitpress/9780262042499.003.0026

Haraway, Donna J. When Species Meet. U of Minnesota P, 2007. 
Jones, Amelia. Body Art. Performing the Subject. U of Minnesota P, 1998. MacCormack, Patricia. "Art, Nature, Ethics: Nonhuman Queerings." Somatechnics, vol. 5, no. 2, 2015, pp. 120-34. https://doi.org/10.3366/ soma.2015.0157

MacCormack, Patricia, and Colin Gardner. Deleuze and the Animal. Edinburgh UP, 2017.

Massumi, Brian. What Animals Teach Us About Politics. Duke UP, 2014. https://doi.org/10.1515/9780822376057

Merleau-Ponty, Maurice. "The Intertwining-The Chiasm." The Visible and the Invisible, translated by Alphonso Lingis, Northwestern UP, 1968, pp. 130-55.

Smith, Kiki. Rapture. 2001, Pace Gallery, New York.

Stachelhaus, Heiner. Joseph Beuys. Abbeville, 1987.

Tisdall, Caroline. Joseph Beuys. Thames and Hudson, 1979.

Warner, Marina. "Metamorphoses of the Monstrous." Fairy Tales, Monsters, and the Genetic Imagination, edited by Mark W. Scala, First Centre for the Visual Arts Vanderbilt UP, 2012, pp. 24-37.

Warner, Marina. "Wolf-girl, Soul-bird: The Mortal Art of Kiki Smith." Kiki Smith: A Gathering, 1980-2005, edited by Siri Engberg, Walker Art Centre, 2005, pp. 42-54.

Wolfe, Cary. Before the Law: Humans and Other Animals in a Biopolitical Frame. U of Chicago P, 2013. https://doi.org/10.7208/ chicago/9780226922423.001.0001

Zipes, Jack. "Fairy-tale Collisions." Fairy Tales, Monsters, and the Genetic Imagination, edited by Mark W. Scala, First Centre for the Visual Arts Vanderbilt UP, 2012, pp. 13-24.

\section{Justyna Stępień is Assistant Professor in Cultural} Studies in the Department of British Literature and Culture, where she received her doctorate in 2012. She is an author of British Pop Art and Postmodernism (2015), an editor of Redefining Kitsch and Camp in Literature and Culture (2014) and co-editor of a special issue of Open Cultural Studies journal (Transmediating Culture(s)?, 2017). She is currently working on her book devoted to posthumanist artistic practices. She belongs to an international research group/collective The Posthuman Art and Research Group (a.k.a. Dori O.) that consists of artists and researchers from all over Europe.

https://orcid.org/0000-0003-2893-3593

justyna.stepien@uni..lodz.pl 